\title{
Disaster management in Bangladesh: developing an effective emergency supply chain network
}

\author{
Mahmud Akhter Shareef ${ }^{1} \cdot$ Yogesh K. Dwivedi ${ }^{2} \cdot$ Rafeed Mahmud $^{3}$. \\ Angela Wright ${ }^{4} \cdot$ Mohammad Mahboob Rahman $^{1} \cdot$ Hatice Kizgin ${ }^{5}$. \\ Nripendra P. Rana 5
}

Published online: 29 October 2018

(c) The Author(s) 2018

\begin{abstract}
This study has addressed and identified the problems in managing the existing emergency supply chain of Bangladesh in all phases of operation in terms of the primary drivers of the supply chain. It has also attempted to conceptualize and suggest an effective emergency supply chain. In this context, a thorough field investigation in several districts was conducted among the employees of the organizations sharing common information with similar protocols and implications (interoperable). Information was collected from the employees of all the participating organizations involved in disaster management through a semi-structured questionnaire based survey. The respondents addressed and illustrated several interconnected reasons which are inhibiting proper forecasting, procurement, storage, identification of affected people, and distribution. The respondents pointed out that the mismatching of objectives in the different organizations resulted in non-interoperability among the participating organizations. These issues are related to the malfunctioning of management with multidimensional organizational conflicts. Reflecting those issues, an emergency supply chain for disaster management is proposed in this study.
\end{abstract}

Keywords Emergency supply chain - Interoperability · Effective supply chain · Disaster management $\cdot$ Logistics management $\cdot$ Relief distribution

\section{Introduction}

During any natural or manmade disaster, different local and foreign donor agencies, NGOs, organizations of United Nations and government organizations try to maintain an effective supply chain to provide shelter and relief to the affected people. It is widely recognized that the success of emergency relief distribution fundamentally depends on maintaining the

Yogesh K. Dwivedi

ykdwivedi@gmail.com

Extended author information available on the last page of the article 
supply network effectively, efficiently, and in a timely fashion (Alessandra 2012; Dubey et al. 2015; Dwivedi et al. 2017; Jabbour et al. 2017b). Research studies on emergency supply chain and relief distribution (Aldrich et al. 2016; Bernados 2017) have investigated many issues concerning the successful operation of this management and the efficient utilization of relief. These studies revealed that identification of the actual needs during a disaster, arrangement of the required items in a timely fashion, and the distribution of these reliefs urgently are the key issues to enhance the success of emergency distribution management and to reduce damage to human beings and other lives, including natural resources.

Several scholarly research studies have explored, in this connection, many technological, organizational, and supply chain factors to develop a comprehensive model of effective emergency disaster management (Bozarth and Handfield 2015; Dubey et al. 2015; Dwivedi et al. 2017; Ekanayake et al. 2013; Jabbour et al. 2017a; Kovács and Spens 2011; Shibin et al. 2017c; Van Wassenhove 2006). These issues have substantially highlighted the effectiveness of supply chain management, the roles of participating organizations, interoperability among them, networking, the utilization of information and communication technology management in monitoring and forecasting a disaster, and, finally, the attitude and performance of the relief workers in managing these activities properly and timely.

The success of the emergency supply chain is highly rooted in the effective management of the participating organizations and their interoperable communications, as, during a disaster, typically many public (both civil and army) and private organizations and NGOs work together to minimize the damages and provide urgent relief to compensate for emergency loss (Balcik et al. 2010; Vanany et al. 2009). Therefore, complex and short term administrative structures are initiated during this period, which often create inter-organizational conflicts which may have a severe negative impact on the appropriate utilization of relief and distribution operations. Planning, organizing, leading, and controlling —all the prominent four phases of effective organizational management face cutting-edge challenges due to open or subtle conflicts, mismatching, and non-cooperation among the employees working under the same administrative jurisdiction (Dwivedi et al. 2017; Hsiao et al. 2017; Van Wassenhove 2006). Cultural conflicts, corruption, scope of ill empowerment, overlapping responsibilities, non-transparent and undefined roles, inappropriate allocation of authorities, undisciplined activities, misuse, and delayed response-all these issues may have a serious compounding impact on the operation of the emergency supply chain (Altay and Labonte 2014; Balcik et al. 2010; Lee 2004).

Existing literature on disaster management (Balcik et al. 2010; Dubey et al. 2014; Lee 2004; McCoy 2008; Majewski et al. 2010; Maon et al. 2009; Stephenson 2005; Van Wassenhove 2006) have investigated many issues which are inhibiting or barring the proper utilization of the resources deployed during an emergency to overcome any physical losses and physical and psychological sufferings. Van Wassenhove (2006) has investigated back-office logistics and distribution management during a disaster and analyzed the humanitarian aspect of emergency operations conducted by army and private organizations. The authors have illustrated that timely distribution is hampered severely due to diversity in aim, objective, and purpose of different participating organizations. The scholarly studies on disaster management (Balcik et al. 2010) and green purchasing (Dubey et al. 2013) have explored the undefined and non-prioritized loop-holes in humanitarian supply chain management and design of procurement. They revealed that forecasting and proper identification of the affected people are the primary problematic areas in this distinct supply chain management. Several studies on structure of emergency supply chain (Alessandra 2012; Balcik et al. 2010; Balcik and Beamon 2008; Beamon and Balcik 2008; Dubey et al. 2017b) postulated that lack of experience and the incompetence of employees of different organizations are the root cause of ineffi- 
ciency. Studies analyzing inventory management (Chen et al. 2017; Johansson and Olsson 2017; Taleizadeh 2018) have also denoted that inappropriate and inadequate allocation of resources and its mismanagement are the key inhibiting forces in achieving operational success. The authors Park et al. (2013) have analyzed the emergency supply chain management of Japan and revealed that the absence of effective organizational structure is a burning issue in the balanced operation of emergency supply chain management during a disaster. Shedding light on these studies, it is explicitly identified that, so far, most of the researchers have investigated many fragmented issues of emergency supply chain management externally; however they overlooked a number of important areas. These are:

1. They did not consider the inefficiency from the individual organizational perspective internally (Bui et al. 2000; Dwivedi et al. 2017). Precisely, the aforementioned studies did not look at the problem of inefficiency from the weaknesses of the participating organizations, i.e., they did not consider that the organization itself can be the problem.

2. The reviewed studies did not reflect the mismatching of interoperability of the participating organizations (Balcik et al. 2010; McCoy 2008). Studies have skipped the administrative problems of the integrated organizational structure.

3. Existing studies have inadequately explored the communication interoperability among the employees of the organizations involved in disaster operations (Alessandra 2012; Surana et al. 2005).

4. Most studies conducting this kind of research considered the traditional nature of supply chain; although an emergency supply chain has significant differences in the nature of the operation, necessity of comprehensiveness, structure of collaboration, and absence and mismatching of established structures (Beamon and Balcik 2008; Majewski et al. 2010; Maon et al. 2009; Oloruntoba and Gray 2006).

5. Studies have addressed issues in light of disasters in developed countries (McLachlin and Larson 2011; Whybark et al. 2010; Xu and Beamon 2006). These scholarly research studies have heuristically figured out the traditional problems in logistics management and resources allocation in emergency supply chain management from a generic perspective.

However, in terms of the operation, organizational involvement and integration, administrative conflict, accountability, transparency, corruption, and resources, experiences of developed countries may have potential differences which necessitate the importance of conducting comprehensive research examining the research gap in existing research in a developing country. Typically, and due to environmental change, Bangladesh is a natural disaster prone country and faces severe and chronic problems due to disasters every year, particularly floods and cyclones. These disasters cause severe damage to property and shelter, loss of human and animal lives, and enormous suffering to poor people in that country. However, since these natural disasters happen unexpectedly and require urgent support, an emergency supply chain should provide extraordinary help and relief, as the damages exceed the ability of the affected and helpless community to meet and fulfill its demand through regular resources. On the other hand, since Bangladesh is a developing country, its ability to meet these urgent requirements through designing an efficient supply chain is very problematic. Considering the primary strategic drivers (parameters of supply chain performance) of a supply chain network, existing studies (Allevi et al. 2018; Dubey et al. 2017a; Georgiadis and Besiou 2008; Surana et al. 2005; Whybark et al. 2010; Xu and Beamon 2006) have identified many problems in facilities, inventory, transportation, information, sourcing, and pricing, while managing supply chain during emergencies in Bangladesh. Particularly, the Bangladeshi emergency supply chain experiences some traditional problems in planning, 
forecasting, procurement, storage and inventory management, and distribution (Dwivedi et al. 2017).

The emergency supply chain management of the Bangladeshi government should traditionally be engaged in managing the entire network and key stakeholders involved in storing relief items, estimating damages and affected people, distributing food and non-food items and other necessary supporting services, and fulfilling the requirements of distressed people during and after any disaster. Generally, during an emergency, many organizations including government organizations (civil and military), donor agencies, and Non-government organizations (NGOs) work together with the local elected bodies to perform all the important tasks related to planning, forecasting, procurement, storage and inventory management, and distribution. A typical problem in the emergency supply chain management in Bangladesh arises due to the absence of an effective system of interoperability among organizations working during an emergency. As a result, the emergency supply chain management of Bangladesh, like other countries, has many problems, but has enough scope to improve and minimize the weaknesses and problems and develop an effective supply chain.

Therefore, this study has two main objectives that will address the research question:

As the first objective, this study will address and identify the problems in managing the existing supply chain of Bangladesh in all phases of operation in terms of the primary drivers of the supply chain. By fulfilling this objective, this study will explore the research question: Why is the existing supply chain of Bangladesh not effective during an emergency operation? The second objective of this study is to conceptualize and suggest an effective emergency supply chain. This objective will meet the research question: What constitutes an effective supply chain during an emergency?

The next section of this exploratory study explores the background information of the existing emergency supply chain in Bangladesh. The methodology applied to encapsulate the research question is articulated in the following section. Result interpretation, discussion, and managerial implications are explained just after the methodology section. Then conclusions are presented. Then, future research guidelines and the limitations of this study are explained.

\section{The emergency supply chain in Bangladesh}

According to an extensive study conducted by Dwivedi et al. (2017), there are mainly two types of supply chain operated by the Bangladeshi government to assist distressed people. The first one is to help poor people regularly throughout the year irrespective of any specific disaster (Humanitarian). The second one is operated during any disaster (Emergency). The regular (First one) supply chain of the Bangladeshi government for relief distribution is primarily based on humanitarian grounds. Its objective is to provide food items like rice/wheat, assorted dry food, non-food items like CI sheets, blankets, tents, and cash to distressed people throughout the year. This government support is termed humanitarian support for distressed and extremely poor people. There are 12 criteria for considering anyone from root level as distressed and extremely poor people. Out of those 12 criteria, only one parameter is disaster affected people. However, to be considered as distressed and extremely poor people, at least 4 criteria must be met (Disaster Management Bureau 2015). The criteria are shown in "Appendix" section. During any natural disaster (Second one), the government of Bangladesh operates their entire emergency supply chain for assessment, procurement, and relief distribution through the same network. The humanitarian supply chain network is operated throughout the year with the aim of providing assistance to generally poor people. Here, the objective is to alleviate poverty. On the other hand, the emergency supply chain is 
operated during and after any natural disaster. The objective is to provide support to those people who are severely affected by a disaster (Disaster Management Bureau 2015).

According to the report prepared by WFP (2017), present relief items include food, nonfood, and cash. Generally, in the month of July, the Department of Disaster Management (DDM) gets the approved budget from the Ministry of Disaster Management and Relief (MoDMR). Based on the budget, the DDM office calls for open tender in September to purchase blankets, CI sheets and other supporting nonfood items. After purchasing these items centrally, inventories are stored in central warehouses in Dhaka, Chittagong, and Khulna. These items are used for both types (regular throughout the year and emergency) of supply chain networks. In the following year, around September, these items are sent to all districts considering the population and poverty index. On the other hand, the government generally procures rice and wheat under the Ministry of Food (MoF). These items are stored in each Upazila food warehouse under the MoF. Considering the area, the population, and the number of Upazila and Union, the DDM office sends an allotment letter for rice to the District Relief and Rehabilitation Officer (DRRO). Whenever needed, DRROs from the district office, send a requisition for rice to the Upazila food warehouse and receive this for distribution. Cash taka is directly handled by the DRRO. Sometimes additional food items or cash taka is paid to each district to buy some other relief items like dry food (Disaster Management Bureau 2015).

During an emergency (during and after any disaster), the Project Implementation Officer (PIO), with the help of volunteers, union parishad chairmen and ward councilors, under the guidance of the UNO, assesses relief requirements and sends it to the DRRO office. Applying intuition and experience, the DRRO adjusts this requirement (generally, the DRRO reduces this quantity significantly), and, after compiling data from all Upazilas, sends it to the Dhaka DDM office. The DDM office again adjusts this amount using intuition and experience (generally the DDM reduces this quantity significantly) and sends the allotment order to the concerned district. This reduction in two phases generally happens because of the bullwhip effect (exaggerated demand from the PIO and then from the DRRO). Estimation, Procurement, and distribution of the regular supply chain of the Bangladeshi government (up to district level) which is operated on humanitarian ground is entirely top down. From a typical point of view, this system is termed the PUSH system, which procures and stores goods in advance of demand from the rural distressed and extremely poor people. This uses a forecast of requirements and moves them through the supply chain to points of the central districts or where they are to be stored as final delivery goods inventory. This inventory is built up to counter predictable variability in demand. There are three kinds of districts categorized as A, B, and C, based on the number of Upazila and Union (Disaster Management Bureau 2015).

Based on this categorization, A type of districts (big) gets 2 Lac taka GR cash and 100 MT GR rice per year as the minimum fixed amount. B type districts get 1.5 lac taka cash and 75 MT rice. C type gets 1 lac taka cash and 50 MT rice. For non-food items like blankets, the minimum quantity of fixed amount per year depends on two criteria, population $(50 \%$ weight) and the poverty index (50\% weight). Last year another fixed amount of cash (5 lac taka) was distributed in each district to purchase dry food for distressed and extremely poor people (Dwivedi et al. 2017). However, for distribution, from district level downstream, it is a bottom up or PULL system where distribution happens in the supply chain only in response to the demand of rural distressed and extremely poor people, on signals from downstream stages. Collecting information of requirements from different wards in municipality or union level, demand is accumulated and placed at the district level. So this humanitarian supply chain management of the Bangladeshi government is a combination of Push-Pull system. 


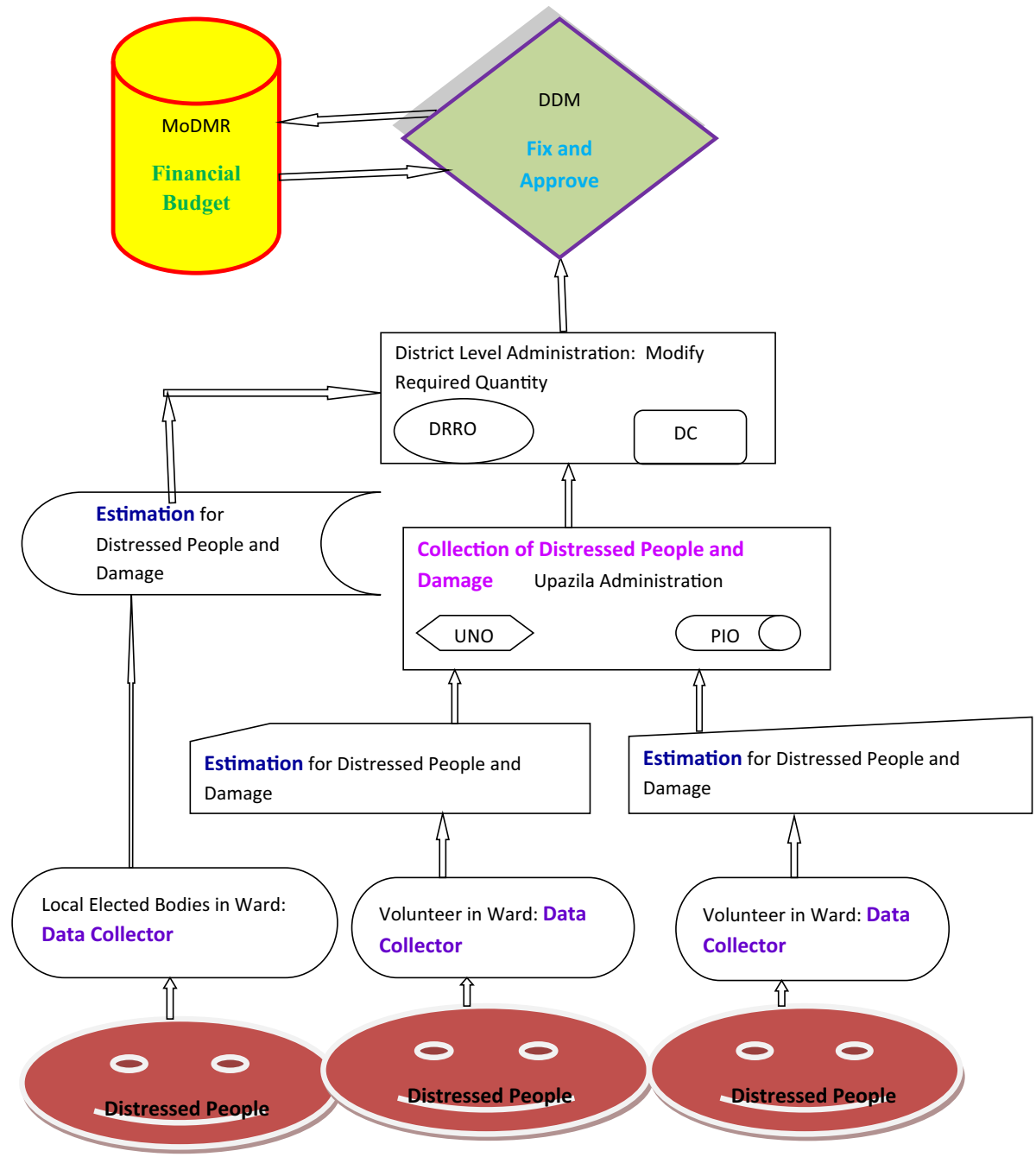

Fig. 1 Emergency reverse/requisition distribution channel

On the other hand, during an emergency, although the same supply chain network is used, its estimation process is bottom up, i.e., a reverse supply network is used (Fig. 1). Then relief items are distributed through forward network (Fig. 2) (Dwivedi et al. 2017; WFP 2017).Therefore, fundamentally, for disaster management, the supply chain network has two components, reverse supply chain network and forward supply chain network. This supply chain network is a PULL system. Nevertheless, total allotment does not fully comply with the PULL system, because at different levels, heuristically at administrative authority levels, the quantity of requirement/demand assessed from field level, i.e., final disbursement points is substantially adjusted (basically reduced) based on authority (Kahn 2008; Tatham and Pettit 2010). Based on the aforementioned information, this study has revealed two components of emergency supply chain networks of the Bangladeshi government as shown in Figs. 1 and 2. 


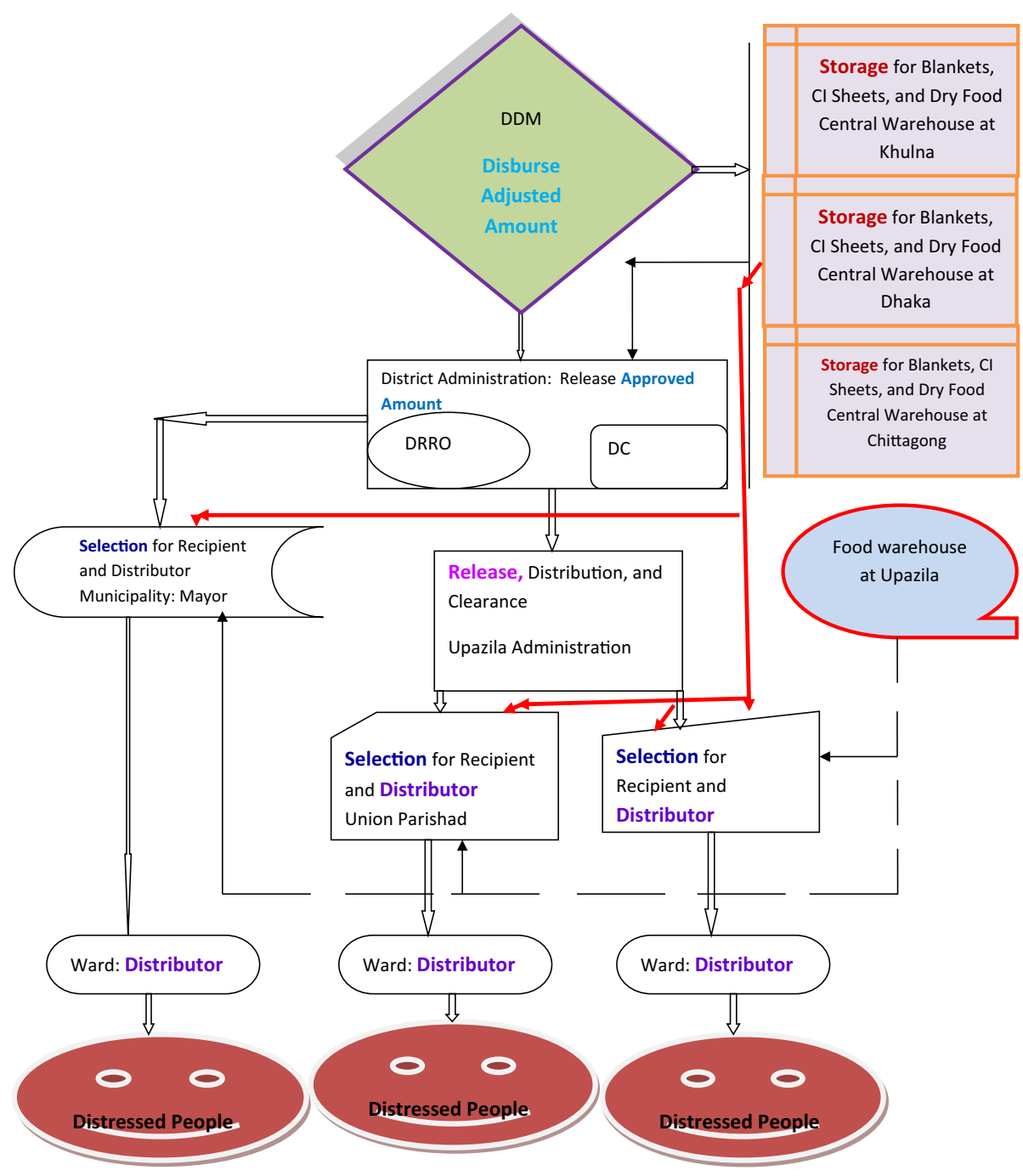

Fig. 2 Emergency forward distribution channel

\section{Methodology}

Since Bangladesh is a natural disaster prone zone and recently experiencing many emergencies due to environmental change, this study has investigated the emergency supply chain in Bangladesh. In this regard, the study has explored all stakeholders' perceptions, i.e., the employees of different government organizations, foreign donor agencies, and NGOs who are responsible for operating the entire disaster management operation in Bangladesh. To capture this evaluation, this present study has conducted a semi-structured questionnaire based survey among the employees of the participating organizations in Bangladesh in the disaster affected districts. This questionnaire was developed from the literature review and through discussion with a well-structured focus group composed of twelve members (six 
Table 1 Summary of data source

\begin{tabular}{|c|c|c|c|c|c|}
\hline Profession & $\begin{array}{l}\text { Status in disaster } \\
\text { management }\end{array}$ & $\begin{array}{l}\text { No. of participated } \\
\text { employees }\end{array}$ & Male & Female & Average age \\
\hline $\begin{array}{l}\text { District commissioner } \\
\text { (DC) }\end{array}$ & Formal Head & 20 & 18 & 2 & 48 \\
\hline $\begin{array}{l}\text { District Relief and } \\
\text { Rehabilitation } \\
\text { Officer (DRRO) }\end{array}$ & District Coordinator & 20 & 20 & 0 & 54 \\
\hline $\begin{array}{l}\text { Project } \\
\text { Implementation } \\
\text { Officer (PIO) }\end{array}$ & Field officer & 50 & 44 & 6 & 36 \\
\hline $\begin{array}{l}\text { Non-government } \\
\text { organization (NGO) }\end{array}$ & $\begin{array}{l}\text { With government, and } \\
\text { independently }\end{array}$ & 40 & 22 & 18 & 29 \\
\hline Donor agencies & $\begin{array}{l}\text { With government, and } \\
\text { independently }\end{array}$ & 10 & 7 & 3 & 42 \\
\hline Defense departments & $\begin{array}{l}\text { Independently, } \\
\text { however } \\
\text { maintaining } \\
\text { coordination with } \\
\text { Civil departments }\end{array}$ & 10 & 10 & 0 & 34 \\
\hline Volunteer & $\begin{array}{l}\text { Under Government } \\
\text { Field Officer and } \\
\text { Independently }\end{array}$ & 30 & 15 & 15 & 27 \\
\hline Local elected body & $\begin{array}{l}\text { Provide data about } \\
\text { affected people and } \\
\text { help in distribution }\end{array}$ & 20 & 12 & 8 & 41 \\
\hline
\end{tabular}

academics in Bangladesh who have experience in managing supply chain and six practitioners who have experience in conducting procurement and relief distribution during a natural disaster).

A sample of 200 people was randomly selected from twenty (20) disaster affected districts in Bangladesh. These people were selected from District commissioners (DCs-public sector), DRROs (public sector, local coordinators), UNOs and PIOs (field level public officers), army officers responsible for relief distributions, officers from local donor agencies, NGOs, International donor organizations, volunteers appointed by government (who are responsible for identifying affected people and distribute reliefs), and local elected bodies. All the above-mentioned people directly participate in different phases of an emergency operation before, during, and after a natural disaster. From each district, ten people were selected from the mentioned organizations. Several discussions were also conducted with the Director, DDM and other office members. Similarly, the authors of this study also met and discussed with several high officials of MoDMR and MoF. The questionnaire was distributed in the month of February, 2018. The appointed research assistants were responsible to collect the response during the following week. However, an interview of approximately 15-30 min was conducted to get a detailed explanation of their responses. A total of 194 responses were collected. The entire empirical study was conducted by the researchers with the help of five research assistants who gathered the data directly. A summary of the collected data is presented in the Table 1. 


\section{Result interpretation, discussion, and managerial implication}

The respondents addressed and illustrated several interconnected reasons which are inhibiting proper forecasting, procurement, storage, identification of affected people, and distribution. The respondents pointed out that the mismatching of objectives in the different organizations resulted in non-interoperability among the participating organizations. These issues are related to the malfunctioning of management with multidimensional organizational conflicts. Since all the members are working to accomplish the same ultimate goal, although with different attitudes, their identifications and evaluations had sufficient congruency in perceiving the existing emergency supply chain during a disaster. Their concepts, heuristic ideas, and precise statements on the central problems for inefficiency and ineffectiveness of emergency supply chain management, focusing on managerial and administrative issues, were analyzed, interpreted, and categorized into groups for commonality and different groups for dissimilarity with justification and significance.

To present these different statements with categorization to reveal some common phenomenon, the information gathered was rearranged according to the principles of matrix thinking. Researchers working on analyzing long statements to reveal commonalities in answers have used this technique (Patton 1981). Text analytics was used as the software to analyze collected information and define commonalities through categorization. This is a very useful tool to interpret qualitative information. Typically, long statements were broken down into small keywords to reveal common and precise issues for inefficiencies in the emergency supply chain during disaster.

The aforementioned problems and issues identified can be grouped into the following 10 (Ten) overall problems:

1. Shortage of facilities for the supply chain

2. Lack of empowerment of downstream execution-level administration

3. Cost management

4. Longer lead time in estimation, procurement, storage, carrying, and distribution

5. Difficulties in targeting and segmenting proper area and proper people

6. Lack of interoperability in coordination and communication among relevant government bodies. In this context, non-interoperability can be defined as the absence or lack of communication and information-sharing with similar protocols and implications among the government and private organizations including defense departments and local and international NGOs involved in the same work (Tatham and Pettit 2010).

7. Improper estimation and selection of items (not need-based)

8. Shortage of human resource and weak organogram

9. Relatively unstable information management

10. Vertical management and top down bureaucracy

These problems occur at different phases of the emergency supply chain management. The following sections will discuss the classification and categorization of the problems into certain specific components of supply chain management. The aforementioned problems and challenges are connected with the following 8 (eight) areas of supply chain parameters. This categorization was primarily conducted manually by analyzing implications of the collected information (shown in Table 2). Text analytics was also used as the software for grouping. A focus group with six university professors from Bangladesh and UK having expertise in supply chain and disaster management was also involved to verify this grouping and categorization. The following Table 2 has illustrated the relations of the aforementioned problems, categorized into ten groups, with eight areas supply chain parameters. Literature 


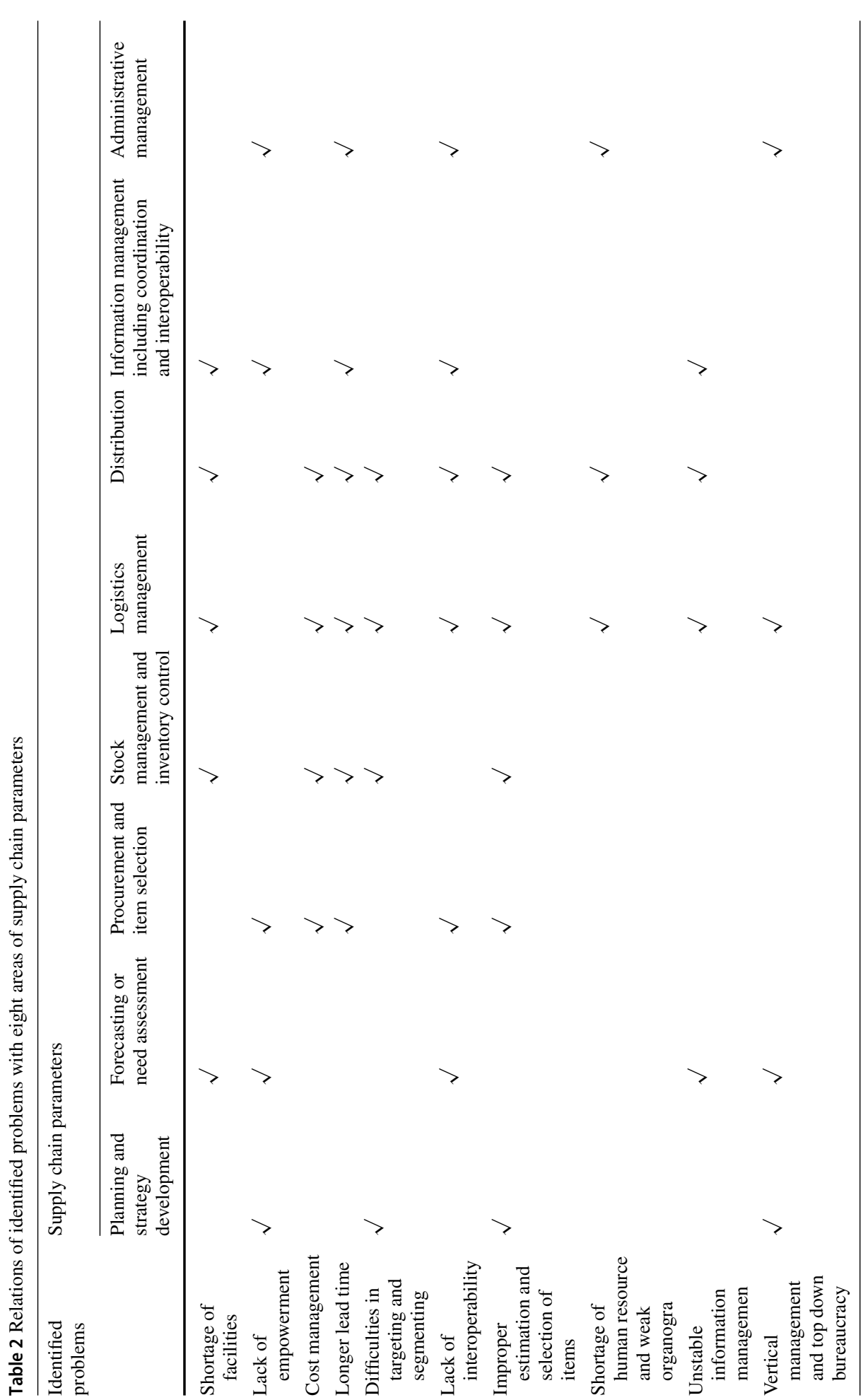


was also reviewed (Dubey et al. 2017a; Dwivedi et al. 2017; Jabbour et al. 2017a; Kovács and Spens 2011; McLachlin and Larson 2011; Maon et al. 2009) to examine and reveal the causal effects of these problems with the supply chain parameters. It is identified that all the individual problems are related to several areas of parameters.

a. Planning and strategy development

1. According to the standing orders on disaster of Bangladesh government, the definition of distressed people is based on 12 criteria (attached in "Appendix" section) where only one parameter is related to 'affected by disaster'. Primarily district coordinators (DRRO) told that, to be qualified for humanitarian relief, out of those 12 criteria, one must fulfill at least 4 criteria. It explicitly shows that the government emergency supply chain for relief distribution is potentially not dependent on a natural disaster.

2. Implied demand uncertainty: According to the DRROs, there are problems in segmenting the population due to the portion of the demand that the supply chain is targeting or plans to satisfy, not the entire demand, as this may sometimes be influenced by local external power. It also came out from the empirical study that local elected bodies try to partially politicize disaster management.

3. During an emergency, this implied demand uncertainty increases since the lead time is essentially shorter. Therefore, although government central strategy is to assist distressed people due to natural disaster, segmentation, targeting, and selection for relief sometimes are influenced by an external recommendation.

4. Volunteers (under CPP) are sufficiently trained and play the key role before, during, and after a cyclone warning, assessing damage, and distributing relief. However, as per the statements of volunteers, they have no direct honorium. Although they are recruited as volunteers, there is no motivational tangible reward for them.

5. To package dry food with several items in the Upazila level, the PIO does not have any allotment for purchasing bags. Bags are important to provide dry food to those families who are bound to stay in flood or cyclone affected areas. Consequently, PIOs somehow manage it from the budget of purchasing food items.

6. Speedboat or regular manual boats are important carriers in flood affected areas, coastal belts, and riversides. DRROs, UNOs, PIOs need to visit those places frequently through this waterborne carrier. However, there is no maintenance cost for any speed boat.

7. Fuel is not supplied for hiring external boats. DRROs told that there is no specific budget for purchasing fuel for external boats hired to travel flood affected areas. It is managed from out of pocket expense.

8. The Labour rates in the food warehouses under the MoF are too high to be managed by the DRRO office. Similarly, in the central warehouse in Chittagong (Dewanhat), since it is a designated food warehouse (under the food department), its labour is controlled by food warehouse labour rates. They are highly monopolized (almost unionized) and raise the wage (Taka 500/MT, whereas the general wage in that place is Taka 300/MT).

\subsection{Summary of the main issues in this category}

1. Since this is emergency work; the policy for overhead costs should be flexible.

2. Food warehouse labour supply and rates are permanent problems for the district and Upazila level authorities to distribute relief transparently. 
3. Demotivation of volunteers is a concern for developing effective supply chain structures.

b. Forecasting or need assessment

1. Director, DDM told that fixed allotment is given based on population, poverty index, and area of the district, not based on historical data.

2. Risk data from historical evidence is not available to any DRRO offices. So, for any newly appointed DRROs, during any disaster, when the PIO/UNO sends any requirement for relief, they reduce it by a certain quantity based on the bullwhip effect from the assessed demand, based on intuition or previous experience.

3. Since historical data for risk is absent, typically DRROs send a requisition to the DDM, Dhaka, several times. Correspondingly there is a waste of processing time, procurement time, and supply and distribution time. This fining is certified by the district commissioners and DRROs.

\subsection{Summary of the main issues in this category}

1. This is one of the major and fundamental problems of supply chain. Relatively inappropriate demand estimation based on forecasting, but not considering historical data of risk (push system) or actual need assessment (pull system) can create weakness in
a. Forming an effective supply chain structure
b. Stocking and inventory management
c. Lead time in providing relief to affected people, although this time span is the primary driver and most sensitive criterion to minimize loss and suffering of disaster affected people.
d. Managing expenditure

2. Just based on intuition or experience, reduction in field level assessment of demand is a problem in estimation. For example, in one district (anonymity is maintained as per the request of the concerned DRRO), demand was placed (as a pull system) in 2016 August for 40,000 blankets, but delivered amount is 22,000. Why this number is deducted is not explained anywhere. This reduction leads to placement of the same requisition several times which ultimately causes transportation cost hiking, lead time extension, and minimization of the professional responsibility to place an accurate requisition.

c. Procurement and item selection

1. PIOs remarked that in dry food packages, they sometimes provide matches (for lighting a fire to cook) which is not suitable in flood areas (Gas Lighter is preferable). In item selection process, filed officers do not have authority or involvement.

2. They do not have life jackets, although it is essential in coastal belts and river side areas. Particularly in the remote Upazilas, the PIO does not have any life jacket to travel to distressed people and distribute relief. It severely hampers relief distribution at the coastal remote places.

3. During a disaster, particularly flooding, there is a potential time gap between availability of rice as relief and the time of consumption since rice needs to be cooked, which is difficult in areas submerged under flood water. More cash in reserve purse is required to buy dry food. 


\subsection{Summary of main issues in this category}

The selection of relief package items(food and nonfood) is very much a random and indiscriminate process. This problem leads to a lower value in expenditure and a lower fulfillment of requirements in the context of cost.

1. Field officers and volunteers told that particularly during floods and cyclones, supplying rice or wheat which needs cooking may not be appropriate. In this context, although relief items may be delivered to the affected people on time (efficient lead time), actual lead time for availability-to-consumption is very poor.

d. Stock management and inventory control

1. Under the condition of anonymity, Director, DDM admitted that food storage in nearby Upazila is dependent on the capacity of the food warehouse (LSD), and this is not aligned with the risk of losses (severity of losses due to disaster X frequency of possibility of occurrence) due to a disaster. In each Upazila, there is a LSD food warehouse; however its capacity is designed to fulfill the requirements of the population of that Upazila, focusing on their poverty, i.e. demand uncertainty. But for actual requirements during disaster, it should also consider implied demand uncertainty influenced by the risk of disaster.

2. The capacity of Upazila level food warehouses is not entirely dependent on actual requirement of food for residents of that Upazila who need relief, i.e., average number of distressed people in that Upazila, i.e., food requirement during disaster. It depends on the convenience of collecting food and population. As a result, sometimes, during a disaster when a huge amount of rice is required to provide assistance to disaster affected people of a certain Upazila, that Upazila food warehouse may not be sufficient to meet the requirements. Then, the PIO and the UNO take the allotment from another Upazila's food warehouse. It creates a longer lead time to deliver food. All the DRROs and PIOs expressed their frustrations for this issue.

3. There is no departmental warehouse in a district or Upazila level under the DDM. Yearly fixed allotments of blankets, CI sheets, are stored in a general room of the district commissioner's office. These relief items are stored under the authority of district commissioners, although practically, DRROs are the coordinators. Around $10 \%$ of inventories (particularly blankets) are damaged due to damp weather and improper storage facilities. Putting an excessively dead load in a very narrow space (particularly CI Sheets) also hampers the structural safety of old district level DC buildings.

4. Rooms used as DC's warehouses are mostly old and not properly maintained. This increases the inventory management cost.

5. Since there is no dedicated warehouse in the district level, and in many districts the DC office is very old (Plinth level is not enough above the highest flood level), storage rooms of blankets and CI sheets may be submerged under water during severe floods.

6. Each year a new allotment (without adjustment) and a renewal of an existing quantity can create the storage and availability of surplus inventory in one district where risk of disaster losses (severity $\mathrm{X}$ frequency of possibility of disaster) is relatively low. The resulting over stocking of inventories in some districts is worthy of examination. 
Through field level investigation, it is identified that in some districts (where the number of disaster affected people is less) (to maintain anonymity, names of the districts are not mentioned) stored numbers of CI sheets and blankets are much higher than their yearly requirements. Cash deposition is also much higher (due to cash-in being much higher than cash-out) than their official entitlement as an $\mathrm{A} / \mathrm{B} / \mathrm{C}$ type of district. On the other hand, in some districts, these stored inventories are much less than the yearly entitlement, since the inventory-in amount is less than the inventory-out due to the severity of the disaster in those districts.

7. Cash taka is typically stored in Banks. So, during emergency, DRROs, UNOs, and PIOs manage cash from local wealthy people. Sometimes this dependency increases the lead time of distribution. DRROs explicitly told that this system should be changed.

8. The DDM office procures CI sheets, blankets, tents, etc., each year in September-October and stores them in central warehouses in Chittagong (3@ 2000 MT capacity), Khulna (3@2000 MT capacity), and Dhaka (4 @ 2000 MT capacity). They allot these stored items in the next year at the same time. So, they keep these inventories for around 1 year.

Regarding blanket storage in a central warehouse by the DDM office, it is purchased centrally by DDM around September. It will be stored for 1 year. These blankets will be delivered in the next year, around September. For example, the DRRO of district $\mathrm{X}$ will receive that. Then he will unload these and store them in the local DC's room up to November (around 3 months). In November, he will send it to different Upazilas for distribution.

GAP Analysis If the purchase of blankets could be decentralized, for example, the local DRRO of district X would purchase those in November (since the cold season is predictable), then the government could save money in the following areas (suppliers can deliver the products to the distribution location) and purchaseto-consumption cycle could be reduced significantly.

Lead time

Existing supply chain purchase-to-consumption time is around 15 months

If all DRROs purchase these blankets locally, this purchase-to-consumption time can be reduced to almost zero.

Overhead cost

In existing supply chain, excess Stocking cost in a central warehouse (including Transportation cost, Labour cost, and Handling loss) for 15 months per blanket.

\subsection{Summary of the main issues in this category}

1. There is enough scope to improve stocking and inventory management under the DDM and the MoF. The existing centralized purchasing policy and the stocking of relief items for around 1 year is causing an increase in transportation and stocking costs, longer lead time to deliver relief to disaster affected people, and additional loss of relief items.

2. Around $20 \%(10 \%+10 \%)$ inventory is lost due to stocking of relief items in the DC's non-dedicated store rooms.

3. Centralized procurement policy is causing price hiking and extra lead time for procurement-to-consumption

e. Logistics management 
1. Representatives from foreign donors told that after a cyclone, roads in remote areas frequently are blocked due to fallen trees and electrical poles. Sometimes, there is a shortage of equipment in disaster prone Upazilas to remove the heavy items from roads to aid quick movement of relief transport.

2. The transportation facility under the DRRO office or the PIO office is very limited, old, and potentially not usable. Frequently, while distributing relief, they seek assistance from other sources for transportation. It is a tragic scenario. Due to this reason, often distribution is disturbed and takes longer time.

3. In many districts, there is no river transport like a boat or speedboat under the DRRO (district level) or the PIO (Upazila level). During a flood or a disaster, the district level relief officer entirely depends on the requisition of boats by elected bodies or other administrative officers. DRROs recommended that this policy should be changed to maintain smooth distribution system.

4. In most of the districts, there are no departmental pickups or functional vehicles under the DRRO. During any tornado or sudden natural disaster, during the night, a pickup under the DRRO is essential. Nevertheless, for direct relief distribution during a sudden disaster, DRROs depend on other sources. It increases lead time for distribution.

\subsection{Summary of main issues in this category}

1. The management of the emergency supply chain substantially depends on logistic management. However, this sector is not properly designed. The absolute shortage of an appropriate transportation facility is a significant problem for demand forecasting, estimation, carrying, and relief distribution.

2. The proper design of road connectivity for relief distribution is also an important concern in this regard.

f. Distribution

1. During a disaster in the remote unions, due to the unavailability of at least one paved road to a shelter center or Upazila headquarter (like Companygang in Sylhet), relief transportation is seriously affected resulting in longer lead times for distribution. This finding is acknowledged by the foreign donors and NGO workers.

2. To reduce the lead time for estimation, procurement, and distribution, manpower under the DRRO office is a major problem. In most of the districts, under the DRRO's office, there is an acute shortage of manpower. As a result, tracking of the estimation, procurement, and distribution is a challenging concern. DRROs recommended that this policy should be reviewed.

3. Manpower is also a concern for the central warehouses. As a result, loading and unloading time increases substantially and the cost of loading also soars.

4. There is no specific allotment for transportation cost. District level officers frequently depend on the Union Parishad Chairman or an out of the pocket source for carrying the cost. In these circumstances, in many cases, the DRRO directly sends loaded trucks to Upazila (UNO) without unloading, although the entire quantity of the truck might not be needed at that time.

\subsection{Summary of the Main issues in this category}

1. The distribution of relief items often experiences severe problems due to the absence of planned design of at least one road to the Upazila shelter center. 
2. The transportation budget is not appropriately allocated for carrying relief. In this regard, dependency on the elected bodies as the receiver hampers the control of the relevant authorities (DRRO, PIO) in relief distribution.

3. Distribution is also sometimes hampered due to the shortage of manpower in the DRRO's office and central warehouse.

4. Distribution at the appropriate time and correct place is affected in some Upazilas due to the remote location of those Upazilas from the DRRO office. The absence of special arrangements for those Upazilas creates serious challenges in distributing relief during an emergency to meet needs.

g. Information management including coordination and interoperability

1. In the district level, they do not have a list of buildings at risk during an earthquake, although there are many old buildings including the local DCs office. So, for any severe earthquake, this absence of a list and preparedness can cause a longer lead time to assess, estimate damage, and distribute relief.

2. The DRRO office is not directly connected with the Bangladesh meteorological department to continuously receive forecasts of a sudden cyclone or a tornado. Although now there is a mobile number (1090) to get a weather forecast, it is not automatic and does not ensure seamless flow of information to the DRRO. In this system, a DRRO needs to monitor this general forecasting self-willingly. Information is not supplied directly to DRROs by the meteorological department to alert them.

3. Citizens are sometimes reluctant to respond immediately. It increases alerting and pre-movement times during a disaster to seek shelter.

4. Uncertainty concerning the demands of affected people is very high, as often information is not readily available and there is a lack of integration and coordination concerning other resources like livestock during a disaster.

\subsection{Summary of the main issues in this category}

1. Availability and accessibility of information and its sharing is a problem for the proper management of the emergency supply chain. All the major stakeholders involved in disaster management clearly denoted that lack of information and its sharing is a vital problem during disaster. There is a significant gap between civil and defense departments to share information.

2. Disaster management is an urgent task. Shortage of on-spot training is a chronic and severe problem for the proper management of the emergency supply chain.

h. Administrative management

1. Most of the DRROs get this district level highest position almost at the end of their careers $(55+)$. However, for effective reaching out to distressed people during an emergency, this position needs to be extremely dynamic. Natural disaster and urgent relief distribution requires flexible and dynamic coordination and communication. Reaching out with relief at the right time and at the right place is the key to executing disaster management. At this age (close to retirement), it is challenging. This can create problem at all stages, such as estimation, procurement, and distribution.

2. DRROs have a limited opportunity for promotion in their job. It is a strong factor in job demotivation and has a detrimental effect on performance. This can create problems in all stages of estimation, procurement, and distribution. 
3. Sometimes local external (not directly affiliated with supply chain) influences can cause problems in assessing losses, estimating disaster affected people, and distributing relief in different localities (wrong segmentation and targeting).

4. The administrative distance between the DC and the DRRO sometimes creates red tape or delay. DRROs have expertise in estimation and distribution, and are responsible for overall relief management. On the other hand, the local DC has the authority to approve any demand and requirement and distribution. Other than DCs, all the major participating agencies suggested that this authority delegation policy should be revised.

5. The DC also has the authority to govern employees under the office of the DRRO, whereas the DRRO is responsible for performance of relief distribution. Authority and responsibility is not given proportionately which may generate:
a. Less amount of estimation
b. Less storage and inventory
c. Delay in filling out a D form and SOS form for requisition
d. Longer lead time for estimation, procurement, and distribution
e. Problems in employee management
f. Inadequacy in information sharing

\subsection{Summary of main issues in this category}

1. Sometimes absence of balanced organogram and inappropriate authority and responsibility delegation may create significant problems in emergency supply chain management during any kind of disaster. While designing the administrative structure, the special nature of this job for assessing, estimating, procuring, and distributing relief before, during, and after disaster are not appropriately considered.

2. Responsibility and authority is not properly balanced.

Based on the analysis of the responses and aforementioned findings, this study has offered the following emergency supply networks for the Bangladesh government (Shown in Figs. 3, 4).

The primary issues addressed and investigated in this semi-structured questionnaire are the major loopholes identified by the participating members in this multi-organizational emergency task as the fundamental causes of inefficient structures in the supply chain. Therefore, the findings of this study provide a deep insight to practitioners concerning a practical disaster management supply network. They can understand the typical problems and interorganizational conflicts during any emergency supply chain management event. It will help in the construction an effective supply network.

\section{Conclusion}

The emergency supply chain management of the Bangladeshi government should customarily be engaged in managing the entire network and be key stakeholders in storing relief items, estimating damages and number of people affected, distributing food and non-food items and other necessary supporting services, and answering the requirements of distressed people during and after any disaster. The existing emergency supply chain of the Bangladeshi government for relief distribution is sufficiently well managed and working nicely. It has many excellent examples to demonstrate its efficiency and effectiveness. However, like any 


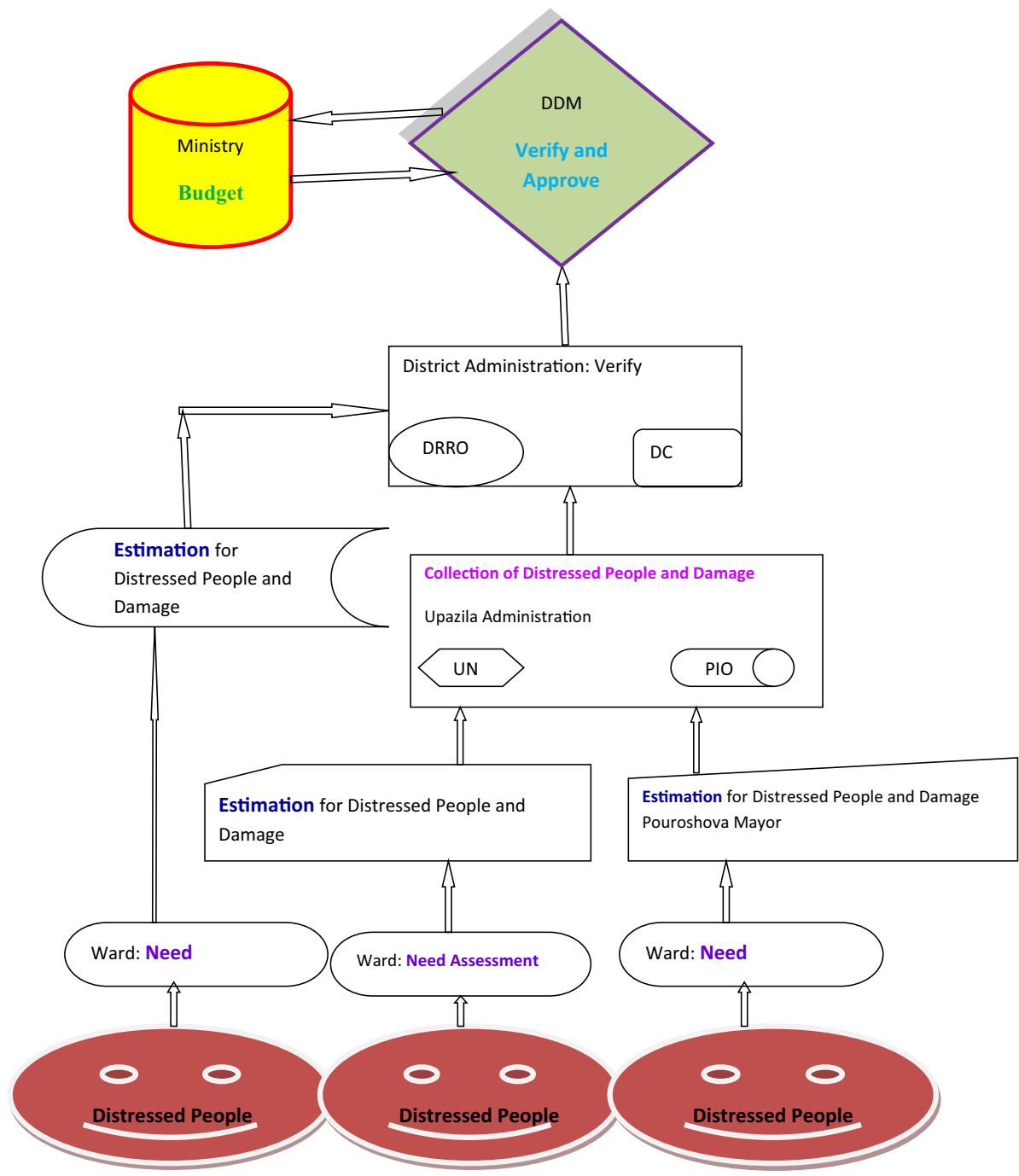

Fig. 3 Emergency reverse/requisition distribution channel after disaster

supply chain system, this emergency supply chain has enough scope to improve, with a view to minimizing the weaknesses and problems.

In this context, a thorough field investigation in several districts was conducted. Information was collected from employees of all the organizations which typically participate in emergency disaster management through a semi-structured questionnaire based survey. Several discussions and meetings with different ministries, departments, and agencies were also conducted. Based on this comprehensive study and SWOT analysis, several major and minor strengths, opportunities, threats and weaknesses of the existing emergency supply chain are addressed. Considering those problems under different drivers of the supply chain, specific categorizations of problems are established. Reflecting those issues, an emergency supply chain for disaster management is proposed in this study. 


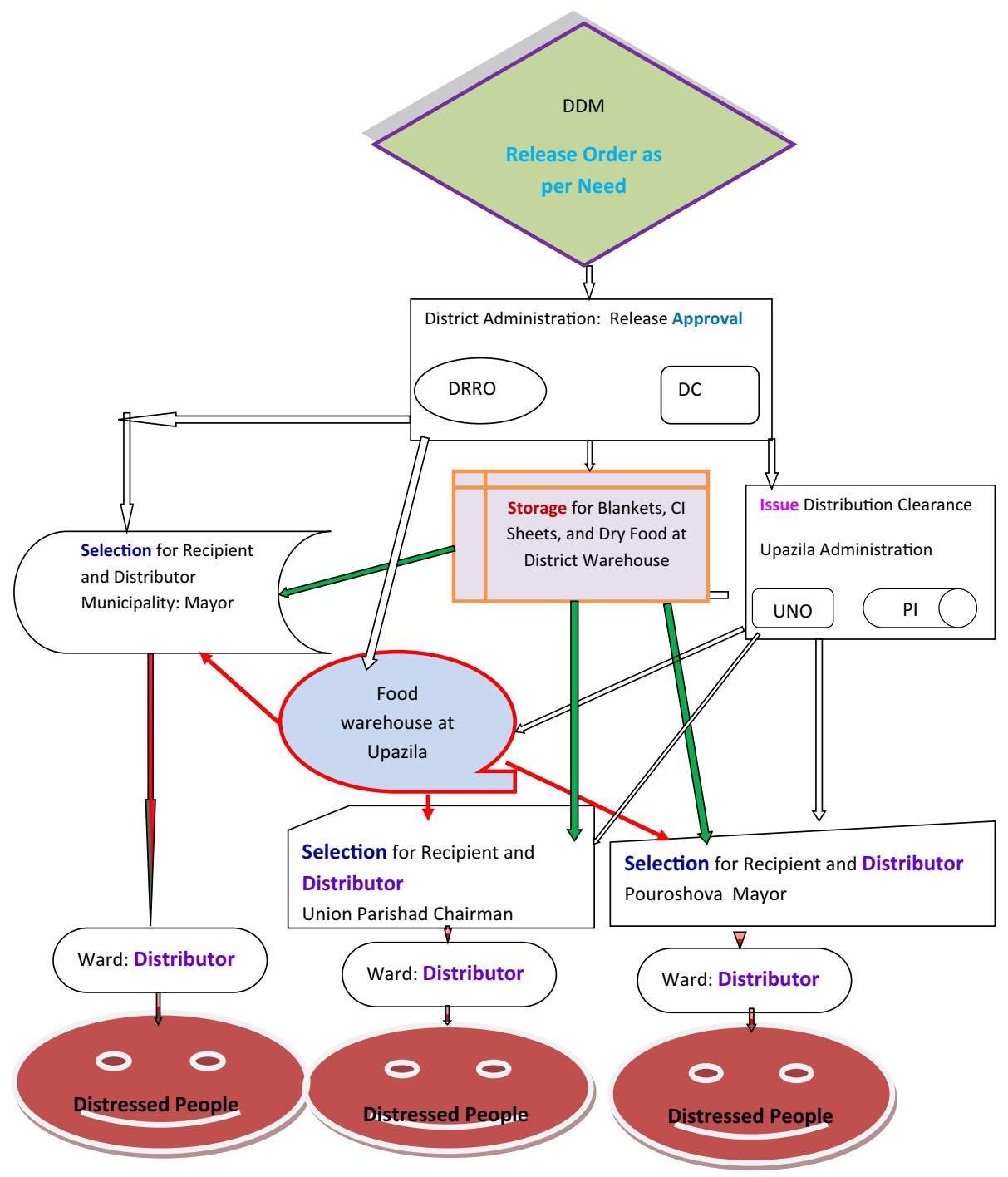

Fig. 4 Emergency forward distribution channel during and after disaster (based on need assessment from source)

This study has demonstrated some potential difference between emergency supply chain management in Bangladesh and the same in developed countries. In the developed countries like Japan, USA, Canada, Australia, Europe, humanitarian supply chain is fundamentally controlled as an actual demand based pull system (Goulding et al. 2017; Jabbour et al. 2017b; Kahn 2008; Park et al. 2013; Reininger et al. 2013; Xu and Beamon 2006), whereas Bangladeshi procurement system is largely dependent on forecasting. Authority delegation and administrative conflict between different participating organizations is a serious challenge both for developed and developing countries (Alessandra 2012; Balcik and Beamon 2008). Selection of item is fundamentally need based in humanitarian supply chain of developed countries (Goulding et al. 2017). Rhetorically, it is suggested by the field officers; however 
for Bangladesh, it is determined centrally. Interoperability among organizations is an acute problem for emergency supply chain; however developed countries have set strong guideline to overcome this challenging issue (Dubey et al. 2017a; Maon et al. 2009). The requirements for proper estimation, distribution, and maintenance of an effective supply chain network and their interoperability are the key issues for disaster management in Bangladesh.

When this study refers to the emergency supply chain management of the Bangladeshi government, it primarily refers to the management of the supply chain of the Bangladeshi government during a natural disaster. This study essentially considers the range of activities designed to maintain control over disaster and emergency situations and to prepare a framework for providing support to at risk persons to help them avoid or recover from the impact of the disaster quickly. It seeks to highlight and draw attention to the supply chain of both forward and reverse networks. When planning and organizing an effective emergency supply chain management for disaster management, the fundamental issues are the institutional arrangement of disaster management, disaster management policies, a comprehensive disaster management program, community based disaster management, and a risk reduction program. Finally, a comprehensive recommendation list is prepared to improve the existing emergency supply chain of the Bangladeshi government for natural disaster management (food, non-food and cash). Among those recommendations, the following key elements can be summarized.

1. For an effective supply chain strategy, the definition of distressed people in a natural disaster should be well structured and predefined. It should be distinguished from regular poverty management on humanitarian grounds. To select beneficiaries and estimate the amount of assistance due to a natural disaster, only the actual requirements of any individual family reflecting losses due to a disaster should be considered.

2. Pre, during, and post disaster period, the roles and responsibilities of all regular employees involved in emergency supply chain should be clearly defined and, accordingly, motivated through different incentives for better performance. In the Pre, during, and post disaster period (cyclone), the roles and responsibilities of volunteers (Fifty Thousand) under a cyclone preparedness program (CPP) are also important. Involvement, integrity, and motivation are the essential components for their full potential to be realised. Although these people are completely involved as volunteers during a cyclone, there will be no question of payment, but for day-night extraordinary dedication, there must be some motivational rewards.

3. The probable relief requirement quantity for each Upazila should be determined based on demand forecasting against risk of losses (historical data). But after disaster, relief should be delivered to the affected Upazila based on the actual need assessment from the source by the PIO.

4. For the Government's emergency supply chain, actual need assessment is very important. Very dynamic, swift, and coordinated field assessment is essential. At different authority levels, this assessed demand derived from the source (Union level) is randomly reduced anticipating an exaggeration of the demand amount (bullwhip). This reduction is not done based on any scientific scale. Field level officers (PIO) should be properly trained to assess actual needs during and after a disaster. If the policy of the government is to provide full support to all affected people due to disaster, this assessed amount from the source should not be reduced based on conjectured bullwhip effect.

5. Item selection, both food and non-food, is critical for covering needs during a disaster. In this regard, relief items during any natural disaster like flood, cyclone, and earthquake should be standardized. There should be a reality-based list of items which 
should be standardized long before any disaster. Several specific and unique issues should be considered to select the relief items, such as nature (for instance raining after cyclone), surroundings (submerged under water), supports (cooking arrangements) etc. Food items where the availability-to-consumption cycle is almost zero (dry food against rice)are most important. This list should be circulated to all stakeholders in order to ensure good coordination during the response.

6. Through field investigation and statistical study of historical data of risk, a committee should be established to prepare a map of the location and required capacity of food warehouses in each Upazila, considering the actual requirement of stocking due to disaster or poverty. Accordingly, based on actual requirement, the capacity of food warehouse should be fixed, and new warehouses should be constructed, if needed. Old warehouses under the Ministry of Food (MoF) should be renovated to minimize maintenance costs and waste of food during floods through proper stock management.

7. Presently the government procurement policy for blankets and CI sheets is centralized (from Dhaka). The procurement and stocking policy of government should be decentralized to minimize lead time of stocking-to-consumption and transportation cost. Based on the requirement/allotment (approved centrally by DDM), each district should individually call for tenders and procure these non-food items locally at the required time.

8. The government has a plan to construct one warehouse in each district (total 64). These warehouses will be 3 storied building, each floor with a capacity to stock around 1000 MT inventory (Ground floor for dry food, 1st floor for blankets and CI sheets, 2nd floor for offices). Instead of keeping these non-food items in a central warehouse in Dhaka, Khulna, and Chittagong, through district level procurement, it can be stored in a district level warehouse (dedicated warehouse, not in a DC's allocated room). While constructing those district level warehouses, a storage strategy should be prepared to minimize lead time for distribution and transportation cost.

9. New allotment and renewal of food, non-food, and cash for each district should be scrutinized, verified, and finally adjusted reflecting actual requirements. This estimation can be conducted by risk analysis of historical data. In a particular year, before a new allotment of food, non-food, and cash from the DDM office, previous balances kept/reserved by the DRRO office at district level under different names of government sectors should be considered to adjust the stocking/inventory amount. This way, surplus stocking in some non-vulnerable districts or under stocking in some vulnerable districts can be standardized.

10. A transport committee should determine transport modalities like pickup, speedboat, boat, and other vehicles, taking into account the special nature of different Upazilas (like river area, coastal belt, hilly area, forest etc.)

11. A shortage of manpower under the DRRO and the PIO office and in central warehouses is a problem for time-bound relief distribution. Relief distribution is an emergency task, so for this kind of supply chain, distribution needs a very dynamic and flexible organogram. An expert committee should determine the actual requirement of manpower for the DRRO and PIO office and warehouse.

12. Roles and responsibilities and coordination should be clearly defined in the organogram of disaster management for all levels. Empowerment of different officers should be clearly based on the involvement and responsibility defined in the emergency supply chain. Particularly, for better efficiency, delegation of proper authority to the DRRO office against their assigned responsibility should be confirmed. Since DRROs have special training on relief distribution and they are playing a key role in the district level disaster operation, their authority should be appropriately aligned with responsibility. 


\section{Limitation and future research direction}

Like any exploratory study, this research has several limitations which may be addressed through future academic endeavors. This study did not incorporate the perceptions of consumers, i.e., affected people. They can provide deep insight into identifying critical areas to be improved. Future research can be conducted highlighting affected people's perception. The selection of the sample from each organization may not be fully representative as the number of employees from different organizations participating in emergency management varies significantly. The specific type of disaster was not considered while capturing employees' perceptions. Emergency operations may vary in different disasters. Therefore, future researchers may wish to consider the effect of a specific disaster type as the moderating variable.

Open Access This article is distributed under the terms of the Creative Commons Attribution 4.0 International License (http://creativecommons.org/licenses/by/4.0/), which permits unrestricted use, distribution, and reproduction in any medium, provided you give appropriate credit to the original author(s) and the source, provide a link to the Creative Commons license, and indicate if changes were made.

\section{Appendix}

At least four criteria must be met to be considered as a distressed and extreme poor person/family to receive humanitarian assistance. These are:

1. The family who has no land or no land other than a living establishment.

2. The family who is dependent on daily labor income.

3. The family who is dependent on a female worker or begging.

4. The family who has no mature earnable male member and the family has scarcity.

5. The family where school going kids have to work to earn money.

6. The family who has no money generating property.

7. The family where the head person is rejected, separated, divorced, and the family has scarcity.

8. The family where the head person is a freedom fighter and has scarcity.

9. The family where the head person is disabled, incapable, and has scarcity.

10. The family who did not receive a micro loan.

11. The family who is now in critical need of food or money due to natural disaster.

12. The family where the members cannot get two daily meals.

\section{References}

Aldrich, D. P., Page, C., \& Paul, C. J. (2016). Social capital and climate change adaptation. In H. von Storch (Ed.), Climate science: Oxford research encyclopedias. Oxford University Press.

Alessandra, C. (2012). Humanitarian logistics: Cross-sector cooperation in disaster reliefmanagement (Chapter 2, P. 13). Berlin: Springer.

Allevi, E., Gnudi, A., Konnov, I. V., \& Oggioni, G. (2018). Evaluating the effects of environmental regulations on a closed-loop supply chain network: A variational inequality approach. Annals of Operations Research, 261(1), 1-43.

Altay, N., \& Labonte, M. (2014). Challenges in humanitarian information management and exchange: Evidence from Haiti. Disasters, 38(S1), S50-S72.

Balcik, B., \& Beamon, B. M. (2008). Facility location in humanitarian relief. International Journal of Logistics: Research and Applications, 11(2), 101-121. 
Balcik, B., Beamon, B. M., Krejci, C. C., Muramatsu, K. M., \& Ramirez, M. (2010). Coordination in humanitarian relief chains: Practices, challenges and opportunities. International Journal of Production Economics, 126(1), 22-34.

Beamon, B. M., \& Balcik, B. (2008). Performance measurement in humanitarian relief chains. International Journal of Public Sector Management, 21(1), 4-25.

Bernados, S. J. (2017). Warning from the Gods: Perceptions and coping strategies of the drought-stricken communities in a Philippine Province: A phenomenological approach. International Journal of Asian Social Science, 7(8), 628-634.

Bozarth, C. C., \& Handfield, R. B. (2015). Introduction to operations and supply chain management. New York: Prentice Hall.

Bui, T., Cho, S., Sankaran, S., \& Sovereign, M. (2000). A framework for designing a global information network for multinational humanitarian assistance/disaster relief'. Information Systems Frontiers, 1(4), 427-442.

Chen, J., Liang, L., \& Yao, D. Q. (2017). Pre-positioning of relief inventories for non-profit organizations: A newsvendor approach. Annals of Operations Research, 259(1), 35-63.

Disaster Management Bureau. (2015). National plan for disaster management, standing orders on disaster. Government of the People's Republic of Bangladesh.

Dubey, R., Ali, S. S., Aital, P., \& Venkatesh, V. G. (2014). Mechanics of humanitarian supply chain agility and resilience and its empirical validation. International Journal of Services and Operations Management, 17(4), 367-384.

Dubey, R., Altay, N., \& Blome, C. (2017a). Swift trust and commitment: The missing links for humanitarian supply chain coordination? Annals of Operations Research. https://doi.org/10.1007/s10479-017-2676-z.

Dubey, R., Bag, S., Ali, S. S., \& Venkatesh, V. G. (2013). Green purchasing is key to superior performance: An empirical study. International Journal of Procurement Management, 6(2), 187-210.

Dubey, R., Gunasekaran, A., \& Ali, S. S. (2015). Exploring the relationship between leadership, operational practices, institutional pressures and environmental performance: A framework for green supply chain. International Journal of Production Economics, 160(February), 120-132.

Dubey, R., Gunasekaran, A., Papadopoulos, T., Childe, S., Shibin, K., \& Wamba, S. (2017b). Sustainable supply chain management: Framework and further research directions. Journal of Cleaner Production, 142(Part 2), 1119-1130.

Dwivedi, Y. K., Shareef, M. A., Mukerji, B., Rana, N. P., \& Kapoor, K. K. (2017). Involvement in emergency supply chain for disaster management: A cognitive dissonance perspective. International Journal of Production Research. https://doi.org/10.1080/00207543.2017.1378958.

Ekanayake, S., Prince, M., Sumathipala, A., Siribaddana, S., \& Morgan, C. (2013). We lost all we had in a second: Coping with grief and loss after a natural disaster. World Psychiatry, 12(1), 69-75.

Georgiadis, P., \& Besiou, M. (2008). Sustainability in electrical and electronic equipment closed-loop supply chains: A system dynamics approach. Journal of Cleaner Production, 16(15), 1665-1678.

Goulding, C., Kelemen, M., \& Toru, K. (2017). Community based response to the Japanese Tsunami: A bottomup approach. European Journal of Operational Research. https://doi.org/10.1016/j.ejor.2017.11.066.

Hsiao, B., Shu, L., Yu, M. M., Shen, L.-K., \& Wang, D.-J. (2017). Performance evaluation of the Taiwan railway administration. Annals of Operations Research, 259(1), 119-156.

Jabbour, C. J. C., Janeiro, R. C., de Sousa Jabbour, A. B. L., Gobbo Junior, J. A., Salgado, M. H., \& Jugend, D. (2017a). Social aspects of sustainable supply chains: Unveiling potential relationships in the Brazilian context. Annals of Operations Research. https://doi.org/10.1007/s10479-017-2660-7.

Jabbour, C. J. C., Sobreiro, V. A., de Sousa Jabbour, A. B. L., de Souza Campos, L. M., Mariano, E. B., \& Renwick, D. W. S. (2017b). An analysis of the literature on humanitarian logistics and supply chain management: Paving the way for future studies. Annals of Operations Research. https://doi.org/10.100 7/s10479-017-2536-X.

Johansson, L., \& Olsson, F. (2017). Quantifying sustainable control of inventory systems with non-linear backorder costs. Annals of Operations Research, 259(1), 217-239.

Kahn, M. S. A. (2008). Disaster preparedness for sustainable development in Bangladesh. Disaster Prevention and Management, 17(5), 662-671.

Kovács, G., \& Spens, K. M. (2011). Trends and developments in humanitarian logistics-A gap analysis. International Journal of Physical Distribution and Logistics Management, 41(1), 32-45.

Lee, H. (2004). The triple-A supply chain. Harvard Business Review, 82(10), 102-112.

Majewski, B., Navangul, K. A., \& Heigh, I. (2010). A peek into the future of humanitarian logistics: Forewarned is forearmed. Supply Chain Forum: An International Journal, 11(3), 4-19.

Maon, F., Lindgreen, A., \& Vanhamme, J. (2009). Developing supply chains in disaster relief operations through cross-sector socially oriented collaborations: A theoretical model. Supply Chain Management, 14(2), 149-167. 
McCoy, J. (2008). Humanitarian response: Improving logistics to save lives. American journal of disaster medicine, 3(5), 283-293.

McLachlin, R., \& Larson, P. D. (2011). Building humanitarian supply chain relationships: Lessons from leading practitioners. Journal of Humanitarian Logistics and Supply Chain Management, 1(1), 32-49.

Oloruntoba, R., \& Gray, R. (2006). Humanitarian aid: An agile supply chain? Supply Chain Management: An International Journal, 11(2), 115-120.

Park, Y., Hong, P., \& Roh, J. J. (2013). Supply chain lessons from the catastrophic natural disaster in Japan. Business Horizons, 56(1), 75-85.

Patton, M. Q. (1981). Creative evaluation. San Anselmo: Sage.

Reininger, B. M., Rahbar, M. H., Lee, M. J., Chen, Z., Alam, S. R., Pope, J., et al. (2013). Social capital and disaster preparedness among low income Mexican Americans in a disaster prone area. Social Science and Medicine, 83, 50-60.

Shibin, K. T., Dubey, R., Gunasekaran, A., et al. (2017c). Examining sustainable supply chain management of SMEs using resource based view and institutional theory. Annals of Operations Research. https://do i.org/10.1007/s10479-017-2706-x.

Stephenson, M. (2005). Making humanitarian relief networks more effective: Operational coordination, trust and sense making. Disasters, 29(4), 337-350.

Surana, A., Kumara, S., Greaves, M., \& Raghavan, U. N. (2005). Supply chain networks: A complex adaptive systems perspective. International Journal of Production Research, 43(15), 4235-4265.

Taleizadeh, A. A. (2018). A constrained integrated imperfect manufacturing-inventory system with preventive maintenance and partial backordering. Annals of Operations Research, 261(1), 303-337.

Tatham, P., \& Pettit, S. (2010). Transforming humanitarian logistics: The journey to supply network management. International Journal of Physical Distribution and Logistics Management, 40, 609-622.

Van Wassenhove, L. N. (2006). Humanitarian aid logistics: Supply chain management in high gear. Journal of the Operational Research Society, 57(5), 475-489.

Vanany, I., Zailani, S., \& Pujawan, N. (2009). Supply chain risk management: Literature review and future research. International Journal of Information Systems and Supply Chain Management, 2(1), 16-33.

WFP. (2017). Forecast-Based Emergency Preparedness Project Bangladesh. www.ifrc.org. Accessed June 2018.

Whybark, D. C., Melnyk, S. A., Day, J., \& Davis, E. (2010). Disaster relief supply chain management: New realities, management challenges, emerging opportunities. Decision Line, 41(3), 4-7.

Xu, L., \& Beamon, B. M. (2006). Supply chain coordination and cooperation mechanisms. The Journal of Supply Chain Management, 42, 4-12.

\title{
Affiliations
}

\section{Mahmud Akhter Shareef ${ }^{1} \cdot$ Yogesh K. Dwivedi $^{2} \cdot$ Rafeed Mahmud $^{3}$. Angela Wright ${ }^{4} \cdot$ Mohammad Mahboob Rahman $^{1} \cdot$ Hatice Kizgin ${ }^{5}$. Nripendra P. Rana 5}

\author{
Mahmud Akhter Shareef \\ mahmud_akh@yahoo.com \\ Rafeed Mahmud \\ mahmud.rafeed@gmail.com \\ Angela Wright \\ Angela.Wright@cit.ie \\ Mohammad Mahboob Rahman \\ mahboob.rahman@northsouth.edu \\ Hatice Kizgin \\ hatice.kizgin@swansea.ac.uk \\ Nripendra P. Rana \\ nrananp@gmail.com
}

1 School of Business and Economics, North South University, Dhaka, Bangladesh 
2 Emerging Markets Research Centre, School of Management, Swansea University, Swansea, UK

3 Human Environment and Resource Development for Society (HERDS), Dhaka, Bangladesh

4 Department of OPD, School of Business, CIT, Cork, Ireland

5 Emerging Markets Research Centre (EMaRC), School of Management, Swansea University Bay Campus, Fabian Way, Swansea SA1 8EN, UK 